\title{
Translation of the World Mental Health Survey Data to Policies: An Exploratory Study of Stakeholders' Perceptions of How Epidemiologic Data Can Be Utilized for Policy in the Field of Mental Health
}

\author{
Lauren Weinberg, MPH, ${ }^{1}$ \\ Harvey Whiteford, MD, MPH, ${ }^{2}$ \\ José Caldas de Almeida, $\mathrm{MD}, \mathrm{PhD},{ }^{3}$ \\ Sergio Aguilar-Gaxiola, $\mathrm{MD}, \mathrm{PhD},{ }^{4}$ \\ Daphna Levinson, $\mathrm{PhD},{ }^{5}$ \\ Siobhan O'Neill, PhD, ${ }^{6}$ \\ Viviane Kovess-Masfety, $\mathrm{MD}, \mathrm{PhD}^{1}$
}

\begin{abstract}
The World Mental Health Survey Consortium, a World Health Organization and Harvard University collaboration, totaling 28 countries participated in a uniform randomized general population survey, making use of translated versions of the WHO Composite International Diagnostic Interview. One of the major purposes of the survey was to help inform policy decision makers regarding mental health. However many obstacles prevent the direct translation of survey data to policies. We report on an investigation of the mechanisms involved in the transformation of survey data into mental health policies. After conducting 11 interviews of individuals representing 12 countries that participated in the survey, we found that although governments did take an active role in the conduct of the survey, this did not necessarily translate into direct policy changes. A number of factors were noted to influence the adoption and implementation of mental health policy changes from the survey data: the establishment of links between the research group and policymakers; the identification of costs of mental disorder; definition of clear solutions;
\end{abstract}

\footnotetext{
${ }^{1}$ Ecole des Hautes Études en Santé Publique, Paris and Rennes, France.

${ }^{2}$ School of Population Health, The University of Queensland, Australia.

${ }^{3}$ Faculdade de Ciências Médicas, NOVA, Lisbon, Portugal.

${ }^{4}$ University of California, Davis Center for Reducing Health Disparities, Sacramento, CA, United States.

${ }^{5}$ Ministry of Health, Mental Health Services Division, Jerusalem, Israel.

${ }^{6}$ Psychology Research Institute, University of Ulster, United Kingdom.
}

Corresponding Author Contact Information: Lauren Weinberg at laweinberg88@gmail. com; Ecole des Hautes Études en Santé Publique, Hotel Dieu 1 Place du Parvis de Notre Dame, 75181 Paris, France. 
and lastly the generation of political will. The range of countries included in this investigation has enabled comparisons in the use of evidence to influence policies in different contexts. Gaining an understanding of why some countries were successful and why others struggled in transforming survey results to policies may help to inform researchers of translational issues of research to mental health policies in the future.

Key Words: World Mental Health Initiative, mental health, epidemiology of mental health, mental health policies

Suggested Citation: Weinberg L, Whiteford H, Caldas de Almeida J, AguilarGaxiola S, Levinson D, O'Neill S, Kessler RC, Kovess-Masfety V. Translation of the World Mental Health Survey data to policies: an exploratory study of stakeholders' perceptions of how epidemiologic data can be utilized for policy in the field of mental health. Public Health Reviews. 2012;34: epub ahead of print.

\section{INTRODUCTION}

\section{The World Mental Health Surveys}

The World Health Organization (WHO) established the World Mental Health (WMH) Survey Consortium in 1998 with the purpose of assessing mental health disorder prevalence, severity, impairment, and treatment in diverse countries around the world ${ }^{1} ; 25$ countries have already participated in the survey and further surveys are still being conducted." The survey took advantage of the WHO Composite International Diagnostic Interview (CIDI), which enabled laypersons to conduct household interviews of the general population and allowed for a protocol that could be applied to all countries in the survey. ${ }^{2}$ The purpose of the WMH initiative was to increase the awareness of and knowledge about mental disorder within the countries surveyed and to enable comparisons of the status of mental health between the participating countries.

As of now, over 154,000 individuals have been interviewed in both the developing and developed countries spanning the six WHO regions. In the first WMH Initiative Report, produced in 2004, assessment of the data from 15 countries $^{* * *}$ indicated that the 12-month prevalence of having any mental

\footnotetext{
${ }^{*}$ Participating Countries: PAHO region: Brazil, Colombia, Mexico, Peru, United States; African Region: Nigeria, South Africa; Eastern Mediterranean Region: Lebanon, Iraq; European Region: Belgium, Bulgaria, France, Germany, Israel, Italy, Netherlands, Northern Ireland, Portugal, Romania, Spain, Ukraine; Western Pacific Region: Australia, China, Japan, New Zealand.

** Belgium, China, Colombia, France, Germany, Israel, Italy, Mexico, Netherlands, New Zealand, Nigeria, South Africa, Spain, Ukraine, United States.
} 
disorder was between 4.3 percent and 26.4 percent. ${ }^{3}$ In addition to this wide span of prevalence, the data indicated there was a large unmet treatment need among the general populations of the countries assessed.

\section{The Policy-Making Process}

A major intention of the WHO in creating the WMH survey was to help countries gather information about the status of mental health for the purposes of informing policy decisions. The survey will serve to focus attention to the scope of mental health problems that are often ignored or underestimated. However transforming survey information into a policy decision is not an easy task. The policy process is highly complex, with many factors influencing its development; what makes this process so complex is that policies usually do not emerge as an outcome of a planned sequence of events. ${ }^{4}$ Many models exist, however, that attempt to make sense of the policy process by using simplified models, such as the rational model developed by Bridgman and Davies ${ }^{5}$ and more complex models, such as the incremental model, which considers the fact that many different interests can impact the policy-making process. ${ }^{6}$ Both of these models share the belief that decision-making can be improved by using knowledge and information to influence policies. ${ }^{7}$ Evidence and research, as argued by the enlightenment model of research utilization indirectly influences research because the translation of evidence to policy is also influenced by the settings in which the evidence and policies emerge., ${ }^{4,8}$

Thus, the accumulation of knowledge does not always easily transform into policies. Gaining an understanding of how research is transformed to policy is therefore an important step to understand how scientific knowledge can be used to make real health gains. ${ }^{9}$ The WHO has in recent years emphasized the importance of creating evidence-based policies, as exemplified by the establishment of a project within the Health Research Systems Analysis Initiative, which seeks to investigate how health research is utilized in policy-making. ${ }^{10}$ Policy-makers are now, more than ever, seen as receptors of research, yet how and for what purposes this research is used by policy-makers is often a controversial topic. Many have cited the oftentimes-antagonistic relationship between policy-makers and the research community. ${ }^{11}$ The essential dilemma in the utilization of research to inform policy is that both researchers and policy-makers are likely to have very different goals, views of the evidence, concepts of time, and career paths. 


\section{From Scientific Evidence to Policies - A Complex Process}

Acknowledging the difficulty of communicating scientific evidence to policy-makers by exploring the interface between research and policy may help to uncover the barriers that persist in the communication, dissemination, and utilization of research to inform policy. Having a greater understanding of how researchers and policy-makers interact with each other may further lead to the creation of solutions to improve the relationship between these two actors. The context in which policy networks exist must therefore be explored. Such networks exist in political, social, and economic situation that are highly changeable and may greatly influence the adoption of policies. ${ }^{12}$ Researchers have recently emphasized the importance of context in the translation of evidence to policy, stating that context shapes the way evidence is introduced, interpreted and applied. ${ }^{13}$ As demonstrated in Dobrow's diagram (Figure 1), both external and internal contextual factors influence how evidence is introduced, interpreted and applied. For example, the 1980 Black Report ${ }^{14}$ conducted by the United Kingdom's Department of Health and Social Security, which uncovered major inequalities in the health of the British population, was dismissed by the Conservative government. Only 20 years later, when a Labor government was in power, were policies made to address the report's findings. In this example, the political environment had a powerful influence in communicating the evidence of the report to the public.

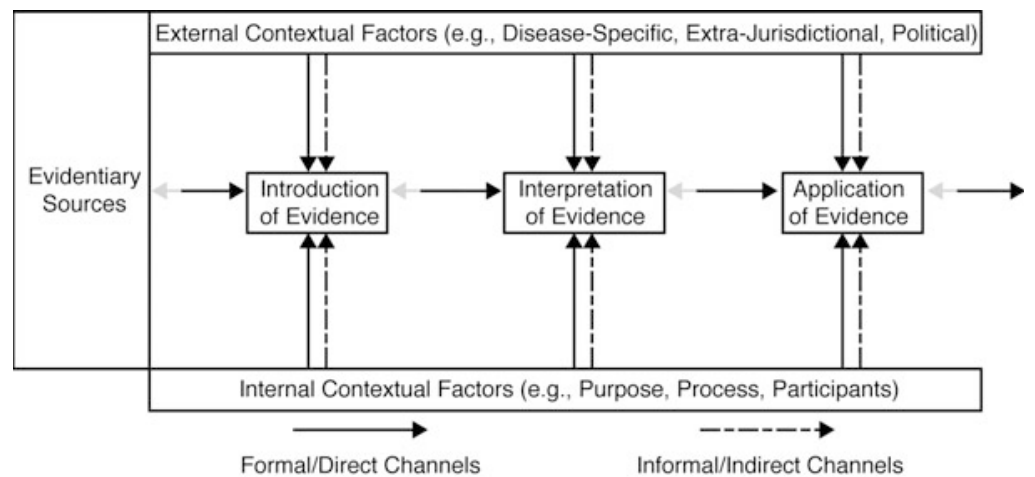

Fig. 1. Conceptual framework for context-based evidence-based decision-making. Source: Dobrow MJ, Goel V, Upshur RE. Evidence-based health policy: context and utilization. Soc Sci Med. 2004;58:207-17. ${ }^{13}$ 
A context-specific barrier that may preclude the creation of evidencebased policies is the capacity of the country; despite the expressed will to follow the indications of the data, political, social, economic or other factors may prevent the implementation of policies. ${ }^{15}$ In this respect the translation of scientific knowledge into a digestible and understandable form for policy-makers and larger stakeholders is essential. In the case of the WMH initiative, the European Union supported the European WMH group, the European Study of the Epidemiology of Mental Disorders (ESEMeD), with disseminating the results to diverse audiences. The resulting European Policy Information Research for Mental Disorders (EPREMED) project ${ }^{16}$ worked to transform the complex epidemiological survey results into simple data sheets for each country. The group arranged press conferences to present these easy to grasp data to a large audience with organized groups of patient, family and lay people to present the data in a way that they could be used at conferences dedicated to ministries and local authorities so they could have a chance to learn about the survey, its main results, and the unmet or inadequately covered mental health needs. Moreover, attempts were made to differentiate levels of needs by separating the needs being covered by the primary care system from those to be covered by the mental health system in those countries where resources were present but not well utilized, thus making the data readily usable by policy-makers. ${ }^{17}$

As of now, there has been no assessment of the WMH survey regarding the translation of research to policy. Our purpose, therefore, is to conduct an investigation of the mechanisms involved in and the contextual factors that influenced the translation of research data from the WMH surveys into mental health policies in their respective countries. In order to gain a better understanding of how the survey data was used to inform policy, the objectives of this study are: to determine how policy-makers participated in the survey; to gain an understanding of the country-contexts in which the survey took place; to determine how data from the surveys were used to inform specific policies; and to assess the implications of the survey data to achieving policy change in the future. It is hypothesized that the success of translating survey data into concrete policies depends greatly upon the policy context within each country, which thus determines how receptive policy-makers are to introducing, interpreting, and applying the evidence. 


\section{METHODS}

\section{WMH Survey Methodology}

The WMH Survey makes use of the WHO's CIDI, which is a fully structured interview designed to be used by trained lay interviewers. The CIDI assesses mental disorders according to the definitions and criteria of the International Classification of Diseases (ICD-10) and the Diagnostic and Statistical Manual of Mental Disorders (DSM-IV). The survey aims to be consistent in all the countries where it is conducted, with uniform training programs, quality control monitoring procedures, and translation and harmonization procedures. Interviews of the general population in each country were based on stratified multistage clustered area probability household samples. Face-to-face interviews were conducted in two parts: Part 1, which assessed core diagnoses, and Part II, which additionally assessed individuals who met criteria for a diagnosis in part I for disorders of secondary interest and a wide range of correlates. ${ }^{18}$

\section{Interview Methods}

The methods of the current study follow a qualitative design based on 12 semi-structured interviews of selected country-representatives who actively participated in the conduction and follow-up stages of the WMH survey in their respective countries. The representatives who were interviewed are experts in the field of mental health, and therefore were thought to provide key insight into the mechanisms involved in translation of research to mental health policy. The interviewers were all affiliated with an academic institution, although some also had links to their country's ministry of health.

Before the study was conducted, a pretest interview schedule was created, which consisted of six central questions along the themes of government participation, specific policies, policies related to specific findings, the usefulness of the survey, cross-country comparisons and the possibility of future studies. In addition, questions were created specifically for the countries that confirmed their interest in being interviewed via email. The questions for the specific countries were created by assessing the country survey results published in online journals and available on the WMH Survey Initiative website. ${ }^{18}$ Two discussion questions were used at the end of some interviews if time permitted. The complete interview schedule can be viewed in Appendix A.

The interviews took place at the WHO WMH Survey Initiative Annual Collaborators Meeting in Brussels, Belgium in July 2012. The purpose of 
the annual meeting was to bring together representatives from the participating countries to summarize their activities for the year including projects completed, projects currently in progress, and articles published. In addition, the annual meeting was an opportunity for collaborators to join work or focus groups that covered specific areas of interest such as mood disorders or service use. The meeting, therefore, was an excellent opportunity to conduct interviews of primary investigators (PIs) from participating countries who expressed an interest in the present study. The interviewees were solicited during the conference by a general announcement during the first meeting, requesting volunteers among country representatives to participate in a short interview regarding the use of the survey to inform policies in their country. Representatives expressing interest in the survey could freely approach either the principal interviewer (Weinberg) or the French representative (Kovess-Masfety) who were both in charge of the study at the conference. Additionally, a few representatives from countries of particular interest, namely Israel, Lebanon, France and Australia were specifically solicited because of their known government participation.

The format of the interviews was primarily informal, with most following the general outline of the interview schedule. All interviews were conducted in English, and no translators were necessary. The interview schedule was designed to include open-ended questions to enable interviewees, to respond freely to issues relating to the use of the survey in their countries. In some cases, it was necessary to omit or add questions because of the specific context of the country. For example, questions about the creation of policies based on the survey were omitted from the interview for the Nigerian representative, whereas in Israel and Northern Ireland, additional questions relating to the specific country context were asked. The length of interviews ranged from ten to 45 minutes depending on the amount of time the interviewee had available. A recording device was used during all interviews upon consent of the interviewee.

Content analysis was used to analyze the information gathered during the interviews. In this method, key phrases and words that were commonly used among all interviewees were determined. The different key phrases and words were then separated into categories according to the different ways in which the WMH survey data influenced policies. These categories include: government support of the survey, government representation within the survey, communication of survey results to governments, and government response to the survey data. In addition, the contents of the interviews were assessed in terms of Dobrow's context-based, evidence-based framework ${ }^{13}$ by determining the external and internal contextual factors in each that influenced the introduction, interpretation and application of the evidence. 


\section{RESULTS}

\section{Government Participation}

\section{Government Support}

A total of 12 country representatives were interviewed representing countries in the following order: Israel, Australia, Japan, China, Northern Ireland, Nigeria, Portugal, France, Lebanon, Mexico, and the Pan American Health Organization (PAHO) region with Peru and Columbia as examples. Responding to the first question relating to government support of the WMH survey, most countries indicated that government participation took the form of financing the survey. Notable exceptions to this finding were the French, Nigerian, and Lebanese surveys. In the French case, government support was non-existent during the actual survey and only took place after the survey was conducted; the pharmaceutical company GlaxoSmithKline financed the entirety of the survey. The Nigerian government recognized the survey but never provided funding because of a lack of budget allocation for mental health at the ministerial level. Most of the health budget in the Nigerian government was devoted to communicable diseases such as cholera and malaria, and so little funding was available to research mental health disorders. The Lebanese government did express genuine interest in mental health issues, and initially promised a large amount of funding for the survey but due to political events, the government could only provide a small amount of support.

\section{Government Representation Within the Survey}

When governments did participate in the survey countries, like Australia, Israel, China, Portugal, Mexico, Peru, and Columbia, they were principally interested in the prevalence rates and service usage data. Governments, when interested in the survey, focused on specific issues; Northern Ireland particularly focused on the issue of post-traumatic stress disorder (PTSD) in areas of the country affected badly by the 'Troubles' of the 1980s and 1990s. The principle government actor involved in the surveys was the ministry of health; information was disseminated to the ministry of health at both formal and informal meetings organized by the survey teams. Two countries had other notable stakeholders involved in the survey: the representative from Japan stated that early in the survey a lawyer representing individuals with mental disorders was present at a number of meetings regarding the survey; in Portugal, two major foundations, which commonly support scientific research, provided a large amount of support for the financing of the survey in addition to the Portuguese government. 


\section{Response of governments to the survey results}

The 12 PIs agreed that the main effect of the survey was to generate greater political will to act on mental health disorders because the survey results brought greater attention to the issue. The representative from Australia stated that because of the survey, the government could no longer ignore the inequities between the provision of services for other equivalently disabling physical disorders such as rheumatoid arthritis and asthma, which had double the treatment rates compared to mental disorders. In the Nigerian case, however, the government was very slow to respond to the survey despite the efforts of an action committee created to raise attention to mental health; the political will of the Nigerian government towards responding to mental health needs was substantially weaker compared to the other countries interviewed, but the Nigerian representative claimed that the situation was beginning to improve very slowly.

The surveys generated the most government interest when the PI or another member of the survey team had a previously established role in the government. The representative from Israel stated that she was able to conduct personal presentations to "people that needed to know" within the government because she already worked within the Ministry of Health's Mental Health Services division. PIs were able to convince governments to agree to fund the survey because of the PI's expertise in statistical methods, such as the PI from Northern Ireland. The reputation of the PI was therefore an essential component to the government's decision to support the survey.

\section{Contextual Factors}

According to Dobrow et al., ${ }^{13}$ there are two decision-making contexts in which evidence-based research exists: internal and external. The internal decision-making context is the environment in which a decision is made and the external decision-making context is the environment in which a decision is applied regarding the introduction, interpretation and utilization of evidence. Internal factors include the purpose of, the participants involved, and the processes involved in the decisions made regarding evidence. The external factors are the decision-specific and political factors that are fixed and that cannot be manipulated by decision-makers. In the following section we will use two country-case examples to illustrate how both internal and external decision-making contexts influenced how the survey results were utilized. 


\section{Internal Factors}

During the interviews, decisions made about the introduction, interpretation, and application of survey data from France in particular was greatly influenced by internal factors. In France, the fact that the survey was financed by the pharmaceutical company GlaxoSmithKline and not by the government meant that policy-makers had to be actively convinced of the survey's importance. Decisions about how the survey was introduced were made in the context of the pharmaceutical industry financing the project. The project leaders in France had been asked by pharmaceutical firms to perform surveys and develop epidemiologic approaches in the context of the renewal of their drug selling prices.

The study confirmed that use of psychotropic drugs was elevated; moreover, half of those to which antidepressants were prescribed did not qualify for depression and a fifth of those taking antidepressants did so for less than two weeks when three weeks was the period required to get a full clinical effect. A report conducted by the French Assemblée Nationale found that a very high number of GPs prescribed anti-depressants to their patients. ${ }^{19}$ The results from the CIDI were important for policy-makers because they did not just reveal that the prevalence of mental disorder was the most elevated in the ESEMeD countries but answered the question: What is a need and demand for care? Because the CIDI is a general population survey, the results of the survey enables researchers to determine the number of untreated individuals who can be diagnosed with a mental health disorder and are not seeking treatment. Thus, the nature of the survey results was seen as a way to gain the interest of policy-makers.

The PI from France emphasized that policy-makers are not so much interested in the prevalence of different types of mental disorders, but rather they are concerned about the percentage of the population that require mental health services. When politicians at the French house of deputies (Assemblée Nationale) learned of the high consumption of anti-depressant and anxiolytic drugs, they decided to conduct an investigation on the matter by using all data available, among them those from the WMH survey. In addition, when the project director held a meeting at the Ministry of Health, the survey was seen to be an "illumination" for policy-makers by providing comparative as well as novel results; thus, the internal contextual factors, namely the nature of the study, present when politicians learned of the survey helped to underline its importance.

In the case of Australia, the internal context that influenced government interest in the survey results were the processes involved in decisions made about how the results would be applied. At the time the survey was 
conducted in 2007, treatment rates for depressive disorders were half that for equivalently disabling physical disorders (using disability weights from the Australian Burden of Disease and Injury Study) such as rheumatoid arthritis and asthma. ${ }^{20}$ Advocates used this data, with the inequity argument being a powerful motivation to policy change. Another key finding, this from the 1997 Australian National Survey of Mental Health and Wellbeing was the days out of role (lost work days) due to common mental disorders. ${ }^{21}$ As a result, the Australian government funded the Work Outcomes Research Cost-benefit (WORC) study, which assessed the prevalence of untreated anxiety and depression of employed populations and the loss of productivity (measured in absenteeism and presenteeism) as a result. This study found the cost to the Australia government was 5.9 million Australian Dollars (AUD) a year, much of which could be averted if treatment was provided. ${ }^{22}$

The PI from Australia emphasized that the combination of both equity and economic arguments, along with the evidence for cost-effective treatments for anxiety and depression, were powerful in changing policy. An example of major policy change was to the national health insurance scheme to fund non-pharmacological treatments for common mental disorders. This $\$ 1.6$ billion AUD Australian governmental expansion in treatment coverage over five years resulted in an increase in population treatment rates for anxiety, depression and substance abuse rising from a pooled estimate of 36 percent in 2007 to 46 percent in $2011 .{ }^{23}$ The processes involved in demonstrating the importance of the data to policy-makers allowed for the creation of policies to address issues found in the survey results - "when you have Australian data hitting both equity and the economic targets its very hard for the Australian government to ignore it" (H. Whiteford, personal communication, July 2012).

\section{External Factors}

The implementation of policies in Peru and Columbia were very much influenced by the external factors of political context and the participants involved in the survey. In the case of Peru, the publication of the data results was delayed as a result of a disconnect within the government organization that implemented the study, the National Institute of Statistics and Informatics, due to a change of directors. It was not until a researcher from the University of Lima took the initiative of gathering, cleaning, and analyzing the data that the survey results were actually published. ${ }^{24}$ The policy environment improved over the years in Peru as a result of a change in government that was more receptive to creating policies related to primary care and mental health, and as a result of a collaboration between 
the Institute of Mental Health and the Institute of Health, PAHO and the University of Lima, that was created to push for the integration of mental health services within primary care. Still, challenges remain in Peru because of the constant turnover of leadership within the Ministry of Health, changing every eight months to a year, leaving little time to plan and implement new policies.

In Columbia there has been much greater success in using the data to create mental health policies. As a direct result of the survey, a national plan for adults and adolescents has been implemented which has led to the integration of mental health services in primary care. There are several explanations as to why the Columbian case has been much more successful than the Peruvian. Firstly, researchers in Columbia developed a very well thought-out algorithm to determine the number of individuals with mental disorders who will go on to seek treatment in the primary care setting. ${ }^{25} \mathrm{By}$ providing a solution to the problem of mental health that is well developed, policy-makers will be more receptive to making changes. Secondly, the written media helped to communicate the results of the survey, making the issue of mental health more transparent to the public. Thirdly, mental health was seen as a priority because of the special access the PI of the survey had to the Minister of Social Protection, which enabled him to present results to leading policy-makers within the government. A key component to the success of the utilization of the survey to inform policy was having close contacts with the government.

The mental health policy changes that occurred in Israel, in a similar way to Peru, must be considered in the political context of the time. The PI stated that although the decision to reform mental health care was already made before the survey was conducted in 2003, the survey helped to inform the government about the utilization levels of services and prevalence of common disorders. The events prior to the survey therefore played an important role. When universal health care was established in Israel in 1995 establishing the right to a comprehensive "basket of services" defined in law, mental health was covered only on a very limited basis, but because services were not provided based on legislation, budget cuts for mental health services could be made more easily. Then in 1998, a decision was made to provide a basket of services for individuals with severe mental disorder to cover both the social and medical aspects of care for these patients, yet common mental disorders like anxiety and depression were still not covered. After the survey was conducted, despite increased pressure to include mental health under universal coverage, the failure of four governments in the period following the survey prevented any legislation 
regarding mental health. It was only in 2012 that a mandate was finally passed to create universal coverage for mental health care. ${ }^{26}$ Although the survey didn't necessarily play a direct role in inducing policy change, the improved political context of the time along with the results which indicated how many people were not getting treated, helped to place pressure on the government to act.

\section{Implications of the Survey for the Future}

All of the country representatives indicated that the survey led to an increase in research interest in mental health in their countries. In China, the representative indicated that as a result of the survey, a greater desire to research mental health disorders has resulted, and has led to a five-year long project with the goal of improving services and obtaining more research funding. More particularly, the results of some countries led to further investigations of specific populations or disorders. The representative from Japan expressed that he would be very interested in conducting a study of individuals living near the Fukushima Daiichi nuclear power plant, the site of the recent earthquake disaster, to compare rates of PTSD among populations directly affected by the disaster and those less affected. Due to issues of sensitivity towards survivors, however, a survey of this population will not be conducted for a few years. Similarly, the representative from Northern Ireland indicated that because the survey results revealed high prevalence of PTSD in certain parts of the country, with rates much higher than in countries like Israel and Lebanon comparable in experience with war and terrorism, there was a great incentive to investigate individuals with the disorder. A further follow-up study, therefore, re-interviewed individuals who were young during the time of the Troubles and asked more detailed question about their experience of the conflict. ${ }^{27}$ The general findings of the WMH survey, which summarizes the overall state of mental health may be a way for countries to begin investigating specific mental health issues in their countries to inform policy more accurately.

\section{DISCUSSION}

\section{Limitations}

The limitations of the current study relate to the limited numbers of interviews that were conducted. Due to time limitations at the conference, only 12 of the 28 countries that participated in the WMH survey were able to be interviewed. In addition, although an announcement was made during 
the conference, nine out of the 12 interviewees of the representatives recruited to be interviewed were personally approached because of their known participation in the survey's communication to government. As a result, there may have been a selection bias, whereby representatives were chosen based on their already active participation in government. Representatives that had a less active role in their country's survey communication to governments were therefore only present in three cases. Although more politically active representatives were chosen, they were able to provide great insight into the process of the transformation of the survey results to policy.

\section{Implications of findings}

The findings from the study demonstrate that the utilization of research findings to inform and implement policies in relation to the WMH survey is a very complex process. Government participation in the survey can help to generate more interest in mental health issues, but does not necessarily mean policies will be adopted and implemented, as was the case in Peru. From the interviews, however, many representatives stated that some factors might help to push mental health issues onto a policy-maker's agenda. These factors include: having established links between the research body conducting the survey and the government, as was particularly the case in Israel, Northern Ireland, and Columbia; identifying the economic costs of under treating mental disorders and providing a feasible solution, as was the case in Australia; and lastly generating political will to act on a mental health problem, as was the case in France. By identifying what has worked to help create mental health policies in countries that had relative success, other countries in the WMH initiative may now apply these solutions in their own context.

\section{Comparison to other studies}

Assessing similar studies that have attempted to evaluate the transformation of epidemiological research to policies, the results of the present study have found comparable findings. An American study examining the use of research to inform policies regarding co-morbid mental and substance abuse disorders, found that providing a clear solution to a mental health problem is an essential component to inform policy-makers about what policies to adopt. ${ }^{28}$ Another study that tried to determine factors influencing the transfer of research findings by health policy-makers in Mali similarly found that the status of a researcher was a major determining factor to 
promote findings to policy-makers. ${ }^{29}$ In addition, it was found that the influence of researchers on policy-makers is also dependent on the policymakers interest in the particular issue, a finding that was particularly noted in the case of Nigeria. The advantage of the present study was that it examined the way research findings, which used the same methodology, were applied to policies in 12 different country settings. This broad investigation allowed for the comparison of similarities and differences in the use of evidence-based policy-making in very different contexts. A limitation to this study was that in most cases, interviews were conducted only with researchers, and not with policy-makers themselves. It would be interesting to interview the policy-makers asking them what aspects of research findings they thought influenced them to take action and create policies.

\section{CONCLUSIONS}

The findings from the present study support the hypothesis that the success of translation of evidence to concrete policies greatly depends on the policy context. Government support, representation and response to the survey as well as internal and external decision-making factors from Dobrow's framework ${ }^{13}$ determined how the WMH survey was utilized by setting the policy stage. The factors that determine the successful application of evidence to policies is complex, and although context is a major factor, other factors, such as those identified in John Kingdon's Multiple Streams Model,,$^{30}$ which takes into account the nature of the evidence itself. The model considers three streams that influence the adoption of research to policies: the problem stream, in which an issue is viewed as a problem to act on; the policy stream, creates a solution to the problem; finally, the politics stream is what determines what issues get on the agenda of policymakers. If research demonstrates the burden of a disease, provides a feasible solution to reducing this burden, and generates political interest, it would be more likely to inform policy. In the case of the present evaluation of how research was used to inform mental health policies, the WMH initiative has the potential to influence these three policy streams by demonstrating the burden of mental health in countries, helping to inform solutions to mental health issues, and by generating political will within the government. The survey cannot guarantee that the conditions for all three policy streams are met, but it can bring countries closer to implementing a mental health policy. 


\section{Appendix A}

\section{Interview Schedule: WHO World Mental Health Survey Initiative Annual Collaborator's Meeting Brussels, Belgium- July 17th-22nd, 2012.}

\section{General Questions for all Countries}

1. Did your government or any regional or local health authorities participate in the WMH survey in your country?

1a. What form of participation was used? (financial, administrative...?)

1b. Was a health authority in charge of the survey?

1c. Were the findings from the survey communicated to other government ministries, and if so, in which manner?

1d. What other specific stakeholders were implicated in the results of your survey?

1e. Was a steering committee in charge of following the survey? If not, were your government or any regional or local health authorities aware that the survey was going on?

1f. How did you disseminate the results among government authorities

2. What specific policies have resulted from the WMH survey conducted in your country?

2a. On what scale (local, regional, national) were these policies delivered?

$2 \mathrm{~b}$. Does your country have a policy planning procedure?

3. Do the policies that result from the WMH survey take into account the specific findings from your country?

3a. If yes, ask specific questions (see below) for each country about significant findings from the survey and if policies were created to address them.

4. Do you feel that the survey was useful to assess the mental health status of your country? (Give concrete examples)

5. How were the comparative results between your country and other participating countries used? (specific examples)

5a. Were these cross-national comparisons a driving force to create new mental health policies in your country?

5 b. Were comparative results regarding health professional utilization considered in the creation of new mental health policies?

6. Are you planning on conducting another mental health survey in your country?

6a. If so, will the comparisons between the new survey and the previous WMH survey be used to inform policy changes?

\section{Potential Discussion Questions (if time permits)}

1. Do you feel that the questions within the survey were pertinent to your country?

2. What changes to the survey do you think could be made to improve its ability to assess areas for policy development? 


\section{Country Specific Questions}

\section{Lebanon}

1. What policies have been put in place to alleviate the impact of war-related trauma on mental health?

2. How does the Mental Health Act address the issue of treatment usage?

3. As a result of the WMH survey has more attention been brought to the issue of mental disorders in Lebanon and has this helped create an improved policy environment?

\section{Australia}

1. Since 2007 (year of the mental health survey) what new policies have been put in place to address the high co-morbidity rates found in the survey.

2. Do you think that the lower than expected response rate of $60 \%$ affected the ability of the survey to inform policy makers?

\section{Japan}

1. What measures have been put in place to increase treatment rate?

2. What policies have been put in place to address suicide, domestic violence, child abuse, and social withdrawal?

3. How do you think the Fukushima nuclear disaster will affect mental health policies regarding PTSD and other related conditions?

\section{Mexico}

1. What policies have been made to address the poor distribution of mental health services in Mexico (mostly concentrated in Mexico City)?

2. What policies have been put in place to address the most common disorders: specific phobias, major depressive disorders, and alcohol abuse?

\section{Northern Ireland}

1. What policies have been created to address the high percentage of youth with mental disorders?

2. What policies have been created to address PTSD resulting from the "Troubles"?

\section{Israel}

1. How did policy-makers use cross-comparative results with countries like Iraq and Lebanon to create policies addressing PTSD?

2. Have any policies been created to address the differences in the mental health care status of Arab-Israelis and Jewish-Israelis?

\section{China:}

1. Have any policies been created to address the issue of psychological stigma of mental health disorders?

2. What policies have been created to improve access to treatment?

3. Do you feel the results of the survey accurately represent the current status of mental health in China so that the results can inform policies? 


\author{
Acronyms List: \\ CIDI = WHO Composite International Diagnostic Interview \\ $\mathrm{ESEMeD}=$ European Study of the Epidemiology of Mental Disorders \\ $\mathrm{PI}=$ primary investigator \\ PTSD $=$ post-traumatic stress disorder \\ $\mathrm{WMH}=$ World Mental Health
}

Acknowledgements: The present study was carried out in conjunction with the World Health Organization World Mental Health (WMH) Survey Initiative, which is supported by the National Institute of Mental Health (NIMH; R01 MH070884), the John D. and Catherine T. MacArthur Foundation, the Pfizer Foundation, the US Public Health Service (R13-MH066849, R01-MH069864, and R01 DA016558), the Fogarty International Center (FIRCA R03-TW006481), the Pan American Health Organization, Eli Lilly and Company, Ortho-McNeil Pharmaceutical, GlaxoSmithKline, and Bristol-Myers Squibb. We thank the staff of the WMH Data Collection and Data Analysis Coordination Centres for assistance with instrumentation, fieldwork, and consultation on data analysis. None of the funders had any role in the design, analysis, interpretation of results, or preparation of this paper. A complete list of all within-country and cross-national WMH publications can be found at URL: http://www.hcp.med.harvard.edu/wmh/.

Conflicts of Interest: None declared.

About the Authors: Lauren Weinberg received her BSc in biomedical sciences and MSc in Global Health and Public Policy from the University of Edinburgh. She received her MPH from the Ecole des Hautes Études en Santé Publique where she is currently a Research Assistant working on the School Child Mental Health Evaluation.

Dr. Harvey Whiteford holds the Kratzmann Chair of Psyciatry and Population Health at the School of Population Health at the University of Queensland. He heads up Policy and Evaluation Research at the Queensland Centre for Mental Health Research. Dr Whiteford has held senior clinical and administrative positions in Australia, including those of Director of Mental Health in the Queensland (1989 to 1996) and Federal governments (1997 to 1999). In 1999 he was appointed to the first mental health position at the World Bank in Washington DC where he worked to develop the Bank's capacity to respond to the rising global burden of mental disorders. Dr. Whiteford has clinical responsibilities in general adult psychiatry and teaches undergraduate and postgraduate students at the University of Queensland. His research activities are in psychiatric epidemiology, burden of disease estimates, mental health policy analysis and the structural reform of mental health services.

Dr. José Caldas de Almeida is Professor of Psychiatry and Dean at the Faculdade de Ciências Médicas, Universidade NOVA of Lisbon. He was the Chief of the Mental Health Unit at the Pan American Health Organization, the Regional Office of the World Health Organization for the Americas, in Washington D.C., from 2000 to 2005. He was a Member of the Executive Group of the European Network on Mental Health Policy between 1998 and 2000, and Temporary Adviser for WHO in Africa, Europe and Latin America. Dr. Caldas de Almeida was the primary investigator of the Portuguese World Mental Health Survey. 
Dr. Sergio Aguilar-Gaxiola is Director of the University of California, Davis Center for Reducing Health Disparities and Professor of Clinical Internal Medicine with expertise on mental health in ethnic populations. He was on-site principal investigator of the Mexican American Prevalence and Services Survey - the largest mental health study conducted in the United States on Mexican Americans. He is the coordinator for Latin America and the Caribbean of the World Health Organization's Mental Health Survey, and coordinates the work of the National Mental Health Institute surveys in Mexico, Columbia, Brazil, Peru, Costa Rica and Portugal.

Dr. Daphna Levinson is affiliated with the Mental Health Services Division of the Israel Ministry of Health.

Dr. Siobhan O'Neill is Professor of Mental Health Sciences at the Psychology Research Institute at the University of Ulster. Her current research projects include the Northern Ireland Study of Health and Stress, and conflict-related trauma in Northern Ireland. She is a chartered Health Psychologist with the British Psychological Society and is a member of the European Health Psychology Society and the Psychology Society of Ireland. Dr. O'Neill was the coordinator of the Northern Ireland World Mental Health Study.

Dr. Viviane Kovess-Masfety is the director of the Department of Epidemiology and Clinical Research at the Ecole des Hautes Études en Santé Publique. She has extensive experience in psychiatric epidemiology and has been responsible for mental health surveys on large population samples including the European Study of the Epidemiology of Mental Disorders (ESEMeD) and the WMH initiative. Dr. Kovess-Masfety is Chair of the World Psychiatric Association.

\section{REFERENCES}

1. Kessler R, Ustun B. The World Mental Health (WMH) Survey Initiative version of the World Health Organization (WHO) Composite International Diagnostic Interview (CIDI). Int J Methods Psychiatr Res. 2004;13:93-121.

2. Robins LN, Wing J, Wittchen HU, Helzer JE, Babor TF, et al. The Composite International Diagnostic Interview. An epidemiologic Instrument suitable for use in conjunction with different diagnostic systems and in different cultures. Arch Gen Psychiatry. 1988;45:1069-77.

3. Kessler RC, Angermeyer M, Anthony JC, DE Graff R, Demyttenaere K, et al. Lifetime prevalence and age-of-onset distributions of mental disorders in the World Health Organization's World Mental Health Survey Initiative. World Psychiatry. 2007;6:168-76.

4. Nutley SM, Webb J. Evidence and the policy process. In Davies HTO, Nutley SM, Smith PC, (editors). What Works: Evidence Based Policy and Practice in Public Services. Bristol: The Policy Press; 2000. p.13-41.

5. Bridgman P, Davies G. Australian Policy Handbook. Sydney: Allen \& Unwin; 1998. 
6. Lindblom CE. The science of muddling through. Public Administration Rev. 1959; 19:79-88.

7. Parsons DW. Public Policy: An Introduction to the Theory and Practice of Policy Analysis. Cheltenham: Edward Elgar; 1995.

8. Weiss $\mathrm{CH}$. The many meanings of research utilization. Public Administration Rev. 1979;39:426-31.

9. Hanney SR, Gonzalez-Block MA, Buxton MJ, Kogan M. The utilisation of health research in policy-making: concepts, examples and methods of assessment. Health Res Policy Syst. 2003;1:1-28.

10. World Health Organization. Health Research Systems Analysis (HRSA) Initiative. Available from URL: http://www.who.int/rpc/health_research/en/ (Accessed 12 March 2013).

11. Choi BC, Pang T, Lin V, Puska P, Sherman G, et al. Can scientists and policy makers work together? J Epidemiol Community Health. 2005;59:632-7.

12. Bowen S, Zwi AB. Pathways to "evidence-informed" policy and practice: a framework for action. PLoS Med. 2005;2:600-5.

13. Dobrow MJ, Goel V, Upshur RE. Evidence-based health policy: context and utilization. Soc Sci Med. 2004;58:207-17.

14. Black D, Morris J, Smith C. Inequalities in Health: Report of a Research Working Group. Department of Health and Social Security. London: Stationary Office; 1980.

15. Wandersman A, Duffy J, Flaspohler P, Noonan R, Lubell K, et al. Bridging the gap between prevention research and practice: the interactive systems framework for dissemination and implementation. Am J Community Psychol. 2008;41:171-81.

16. European Policy Information Research for Mental Disorders (EPREMED) Available from URL: http://www.epremed.org/ (Accessed 12 March 2013).

17. Kovess-Masfety V, Alonso J, Brugha TS, Angermeyer MC, Haro JM, SevillaDedieu C. Differences in lifetime use of services for mental health problems in six European countries. Psychiatr Serv. 2007;58:213-20.

18. The World Mental Health Survey Initiative. Harvard School of Medicine. Available from URL: http://www.hcp.med.harvard.edu/wmh/ (Accessed 12 March 2013).

19. Briot M. Rapport sur les bon usage des medicaments psychotropes. Assemblée Nationale, Office Parlementaire d'Évaluation des Politiques de Santé; 2006. [In French] Available from URL: http://www.assemblee-nationale.fr/12/rapoff/i3187.asp (Accessed 10 April 2013).

20. Australian Gorvernment, Australian Institute of Health and Welfare. The burden of disease and injury in Australia. AIHM; 1996 and 2003. Available from URL: http://www.aihw.gov.au/burden-of-disease/ (Accessed 12 March 2013).

21. Australian Bureau of Statistics. National Survey of Mental Health and Wellbeing: summary of results, 2007. Australian Bureau of Statistics; 23 October 2008, last updated 25 June 2009. Available from URL: http://www. abs.gov.au/ausstats/abs@.nsf/mf/4326.0 (Accessed 12 March 2013). 
22. Hilton MF, Scuffham PA, Vecchio N, Whiteford HA. Using the interaction of mental health symptoms and treatments status to estimate lost employee productivity. Aust N Z J Psychiatry. 2010;44:151-61.

23. Council of Australian Governments. National Action Plan for Mental Health 2006-2011. Standing Council on Health: May 2012. Available from URL: http://www.coag.gov.au/sites/default/files/NAP\%20on\%20Mental\%20

Health\%20-\%20Fourth\%20Progress\%20Report.pdf (Accessed 3 April 2013).

24. Alarcón RD, Aguilar-Gaxiola SA. Mental health policy developments in Latin America. Bull World Health Organ. 2000;78:483-90.

25. Posada-Villa JA, Aguilar-Gaxiola SA, Magana CG, Gomez LC. Prevalence of mental disorders and use of services: preliminary results from the National Study of Mental Health Colombia, 2003. Rev Colomb Psiquiatr. 2004;33:24162. [In Spanish]

26. Aviram U, Ginath Y, Roe D. Mental health reforms in Europe: Israel's rehabilitation in the community of persons with mental disabilities law: challenges and opportunities. Psychiatr Serv. 2012;63:110-2.

27. Ferry F, Bolton D, Bunting B, O'Niell S, Murphy S. The experience and psychological impact of 'Troubles' related trauma in Northern Ireland: a review. Irish J Psychol. 2010;31:95-110.

28. Clark HW, Power AK, Le Fauve CE, Lopez EI. Policy and practice implications of epidemiological surveys on co-occurring mental and substance use disorders. J Subst Abuse Treat. 2008;34:3-13.

29. Albert MA, Fretheim A, Maïga D. Factors influencing the utilization of research findings by health policy-makers in a developing country: the selection of Mali's essential medicines. Health Res Policy Syst. 2007;5:2.

30. Kingdon JW. Agendas, Alternatives and Public Policies. New York, NY: HarperCollinsCollege; 1995. 